\title{
EDITORIAL
}

\section{Pediatric emergency medicine: a world of potential}

\author{
Niranjan Kissoon, MD; ${ }^{*}$ Ran D. Goldman, $\mathrm{MD}^{\dagger}$
}

Version fRANÇAISE À LA PAGE 456

$\mathrm{P}$ ediatric emergency medicine (PEM) is a mature discipline in North America, although it does not exist, or is still in its infancy, in many regions of the world. Maturity arrives with expectations, which, if unfulfilled, are likely to result in unrealized potential and indeed early senility. PEM practitioners need to consider what is expected of the discipline to achieve full potential.

A myopic outlook leads one to believe that PEM entails taking care of children in the pediatric emergency department (PED). Working in a PED has its challenges, with limited resources and increased demands. Inpatient bed shortages, curtailed laboratory services, inadequate staff and large patient volumes place tremendous stress on the PED in its role of triaging, treating and ensuring that every child gets appropriate care.

Yet the PED is an integral part of the hospital system and works closely with the pediatric intensive care unit (ICU), pediatric inpatient wards and operating rooms to ensure a seamless interface to other pediatric subspecialties. Many of the procedures that were once the realm of specialty services are now performed in the emergency department (ED). Procedures such as endotracheal intubation and procedural sedation that were facilitated by anesthesiologists are now an integral part of the PED capability. Stabilization and skilled resuscitation, once the domain of specialized intensivists, are now managed equally well in the ED by PEM-trained physicians. Suturing lacerations and reducing closed fractures are now routine for pediatric emergentologists.

The importance of having the PED work closely with the pediatric ICU and the rest of the hospital has been previously emphasized. ${ }^{1}$ The close working relationship between ICU and EDs is not a cosmetic or romantic notion.
Indeed, a recent adult study showed that a critically ill ED patient who was delayed for 6 or more hours before transfer to the ICU had an increased ICU and hospital length of stay as well as higher morbidity and mortality. ${ }^{2}$ Twentyfour hours a day, 7 days a week, the PED is a central cog in the continuum of care from the outside world to the hospital for care workers and practitioners in offices and referral clinics.

However, even this view of the role of PEM limits its full potential. On a macro scale, there are many factors that influence the quality of care that someone receives (Fig. 1). While some of these factors may seem beyond the scope of PEM, we would argue they are not. As pediatric emergency practitioners we should be involved in all aspects of health care, including determining the appropriate physical facilities, responding to community demands, looking at health resources, finances, technology, drug procurement, clinical guidelines and the overarching softer aspects of care for children. Indeed, many of us are already involved at a provincial, national and international level in an attempt to influence many of these factors.

A pediatric emergency physician should be involved in the entire continuum of care of the acutely ill and injured, from prevention to rehabilitation (Fig. 2). Advocacy by pediatric emergentologist leaders with respect to accident prevention and health promotion endeavours such as vaccination campaigns, deterrence of drowning, seat belt legislation and limitation of sports related injuries has provided untold benefit to our pediatric patients.

PED physicians should work closely with paramedic teams to ensure appropriate care and resuscitation on scene. Guiding stabilization at the scene and organizing safe transport can be vital for the sickest or most injured

*Acute and Critical Care Programs, Department of Pediatrics, University of British Columbia, Vancouver, BC, +Pediatric Emergency Department, BC Children's Hospital, Vancouver, BC

Can J Emerg Med 2007;9(6):453-5 
children. Indeed the transport system for many children's hospitals is administered by the PED.

The importance of a functional transport system and its relationship to the PED is starkly underlined by the outcomes in areas in which one or the other is not well developed. In the state of Andhara Radesh, India, where PEM and pediatric intensive care services are excellent, but where emergency transport is lacking, the outcomes are less than ideal: $52 \%$ mortality for infants less than 1 year of age and $33 \%$ mortality for children aged 1-5 years. Moreover, almost one-half of the children died within 12 hours of admission to the hospital, underlining the late presentation owing to inadequate prehospital services. ${ }^{3}$ Proper transport systems for children is recognized as a neglected global issue. ${ }^{4}$ In some cases it is done using bicycles with trailers, tricycles with platforms, motorboats, ox carts, ${ }^{5}$ taxis and buses, ${ }^{6}$ while it is totally absent in many areas. ${ }^{7}$ We must become advocates for better transport systems to ensure safe and stable arrival.

Advocacy for resources (e.g., staff, building, equipment, etc.) to ensure proper triage and treatment in PEM needs further emphasis, not only for tertiary care pediatric centres, but also for outlying institutions so that all children can aspire to the same standard of care. A vibrant network, including telemedicine and involvement in education programs throughout our sphere of influence, provincially and nationally, cannot be overemphasized.

The pediatric emergency physician should play a pivotal role in education at all levels: students, residents and physicians in practice. In addition, the education of allied health providers such as nursing staff, respiratory therapists and paramedics is of vital importance for the provision of the care of children. Assuming leadership roles in advanced trauma life support (ATLS), advanced pediatric life support (APLS) and pediatric advanced life support (PALS) courses as well as airway and resuscitation courses and simulation programs are some of the areas of education in which pediatric emergency physicians have emerged as national leaders. The education of crew resource teams from outlying centres to prepare for the

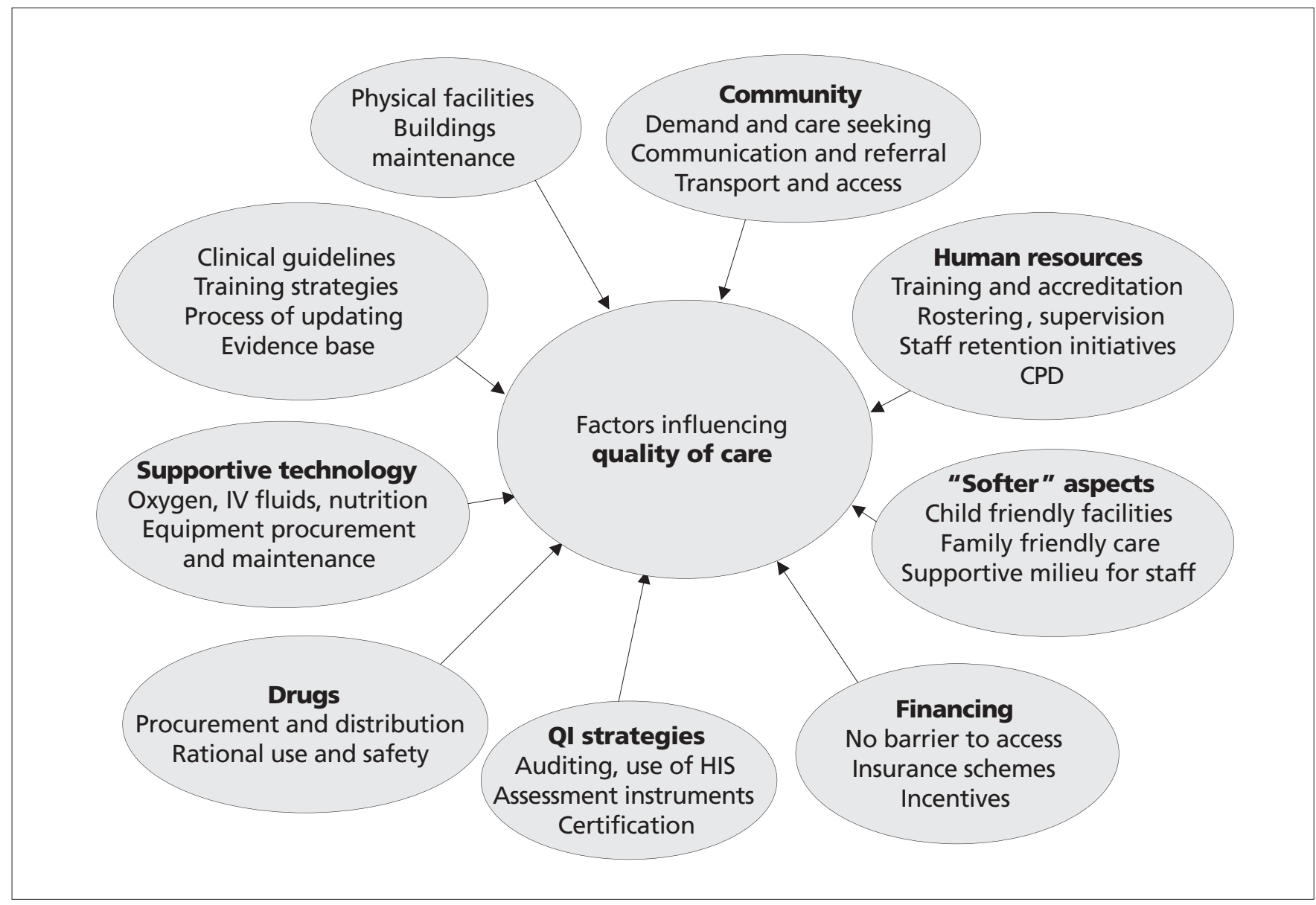

Fig. 1. Factors influencing quality of care. CPD = continuting professional development; IV = intravenous; HIS = health information systems; QI = quality improvement. 


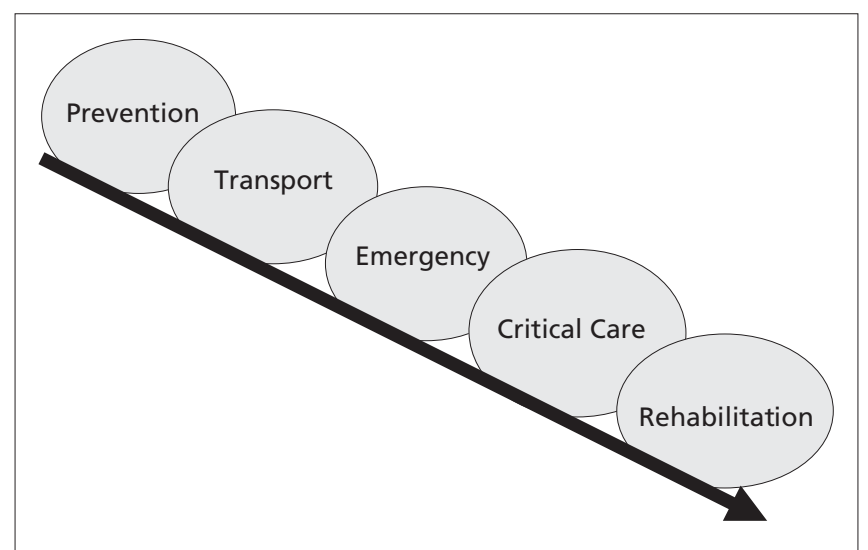

Fig. 2. The continuum of care of the acutely ill child.

treatment of a critically ill child is also a role that needs to be assumed by a pediatric emergency physician in tertiary care centres.

The expertise of the pediatric emergency physician is also required for local, regional and national disaster planning, pandemics and toxicological issues that are specific to children. The PED becomes even more important in these situations, since it is a point of first contact for most individuals who are seeking acute care. Rational planning for untoward events and disasters in any community should include the PED as an integral part of the entire process. Such expertise can then be applied in the international setting in times of crisis.

Significant contributions in prevention, evaluation and treatment can be made because of accrued experience with common conditions. The ED is a fertile ground for answering questions pertaining to asthma, respiratory distress, croup, epiglottitis, trauma, poisonings, cardiopulmonary resuscitation and epidemiological studies pertaining to accident prevention. The Pediatric Emergency Research Consortium (PERC) in Canada ${ }^{8}$ and the Pediatric Emergency Care Applied Research Network (PECARN) ${ }^{9}$ in the United States are examples of involvement in research endeavours.

Involvement of the pediatric emergency physician in such diverse areas as outlined may seem a daunting proposition. However, it is a reflection of the growth of the subspecialty and its central importance to the medical community and society at large. Ultimately, the role of the PED should not be confined within the walls of institutions or limited by our imagination. It should embrace the wide range of opportunities available to improve the lives of the ill and injured, regardless of geographic location.

\section{References}

1. Kissoon N. The pediatric emergency department/pediatric intensive care unit interface: "the double door mentality." Pediatr Emerg Care 2006;22:613-5.

2. Chalfin DB, Trzeciak S, Likourazos A, et al. Impact of delayed transfer of critically ill patients from the emergency department to the intensive care unit. Crit Care Med 2007;35:1477-83.

3. Ranganath D, Rao PS, Beligere N, et al. Under five mortality (UFM) in a pediatric intensive care unit (PICU) serving urban and rural population in India. E-PAS 2007:618418.8.

4. Duke T. Transport of seriously ill children: a neglected global issue. Intensive Care Med 2003;29:1414-6.

5. Razzak JA, Kellermann AL. Emergency medical care in developing countries: is it worthwhile? Bull World Health Organ 2002;80:900-5.

6. Mock CN, Tiska M, Adu-Ampofo M, et al. Improvements in prehospital trauma care in an African country with no formal emergency medical services. J Trauma 2002;53:90-7.

7. Nolan T, Angos P, Cunha AJ, et al. Quality of hospital care for seriously ill children in less-developed countries. Lancet 2001;357:106-10.

8. Pediatric Emergency Research Consortium Canada (PERC). Available: www.perc.med.ualberta.ca (accessed 2007 Oct 17).

9. Pediatric Emergency Care Applied Research Network (PECARN). Available: www.pecarn.org/ (accessed 2007 Oct 17).

Correspondence to: Dr. Niranjan Kissoon, University of British Columbia, Children's Hospital, Rm K4-105, 4480 Oak Street, Vancouver BC V6H 3V4; nkissoon@cw.bc.ca 